\title{
When to help farm animals grow faster
}

The European Commission has broken with precedent by sponsoring an independent scientific conference on the role of growth-promoting substances in animal husbandry.

WHEN athletes use anabolic steroids to enhance their performance on track and field and are found out, they suffer dire penalties. Often, they are banned from further competition, either for some years or even for the rest of time. Olympic performers tearfully on the way home after being stripped of medals they supposed they had won are a common sight. The principle underlying these draconian measures is simple; athletic competitions are supposed to be tests of natural athleticism, whose artificial enhancement by means of drugs is manifestly unfair. There is naturally less concern with the damage athletes may do to themselves by the long-term use of drugs.

But there are other fields in which drugs that improve performance are nevertheless widely and legally used. Animal husbandry is the outstanding example. The various steroids that human weight-lifters may use to improve their competitiveness will also enable beef cattle to accumulate muscle tissue more quickly than would otherwise be the case. The result is beef in which the ratio of fat to lean meat is enviably low, and which, to the profit of enterprising farmers, can reach the market relatively quickly. The use of steroids and other classes of drugs to enhance the growth of commercially domesticated animals is now widespread, but not in Western Europe; since 1989 , the use of growth-promoting substances in livestock feed has been prohibited by a series of directives by the European Union (EU).

The origins of the EU ban are complex. Environmental pressure groups were among those who proclaimed that the residues of growth-enhancing substances in meat offered for consumption would, over the years, damage the health of those who ate it. And the effects are not always simply toxicological. Who can say whether traces of antibiotics in meat do not encourage the emergence of resistant microorganisms, thus disadvantaging even vegetarians? There is also concern that growth-promoters will damage the health of animals treated with them. In the late 1980s, the European Parliament was a powerful sounding-board for these anxieties. Farmers' organizations and EU officials might well have been more vigorous in their opposition to the ban if it had not been for Europe's surplus production of beef.

Not all the consequences of the European ban have been beneficent. For one thing, meat producers outside Europe have protested that Europe's ban on imported meat produced with the help of growthenhancing chemicals is a "non-tariff restraint on trade". Not surprisingly, the ban has also strengthened the pre-existing illicit European trade in growth-enhancing chemicals. From time to time, farmers and others are prosecuted for feeding these materials to livestock. Because the initiative for prosecution lies with national inspectors, nobody knows how general is evasion; there are fears that the illicit market may be supplied with cocktails of growth-enhancers made up by unregulated cowboy manufacturers, with dangers comparable to those all-too-apparent in the illicit trade in what are laughably called 'recreational' drugs.

That is the background to an unusual scientific conference to be sponsored from 29 November to 1 December by the agriculture directorate of the European Commission, and of which I will be the chairman. The intention is to review the scientific evidence bearing on the use of growth-promoting substances in animal husbandry, and to make an assessment of the present state of knowledge. To ensure that it cannot afterwards be accused of being partial, the commission has delegated organization of the conference entirely to a small steering committee, whose members (apart from myself) are Professor François André (Laboratoire des Dosages Hormonaux, Nantes); Professor Carlos van Peteghem (Food Analysis Laboratory, Ghent); and Dr Francis W. Kenny (Central Meat Control Laboratory, Dublin).

The programme of the conference is built around three topics, each of which will be introduced by a review paper by a person who will then become the chairman of a working group of the issue. Thus Professor James Roche (Dublin) will deal with the variety of growth promoters now in use or on the horizon (which, of course, includes the transplantation of growth-promoting genes); Mr Jan Rud Andersen (Danish Meat Research Institute) with the analytical methods of detection; and Professor Fritz Ungemach (Institut für Pharmakologie, University of Leipzig) with the health risks of growth-promoters.

What follows is an account of the ways in which the conference is unusual ... and an appeal for help. First, the commission's delegation of responsibility to the steering committee has been complete; there have been occasions when the commission's officials have been asked to let us pursue our discussions on our own. The 60 or so par- ticipants are being invited on our recommendation, on the basis of what we know of their scientific contributions in the field; they come not only from Europe, but from other major meat producers such as Australia, Canada and New Zealand as well as the United States.

After some heart-searching, however, we have decided not to invite as participants scientists affiliated with the major veterinary drug manufacturers or other interested parties, farmers' organizations for example. That concession to political correctness does not imply that such people are not good scientists, or are unable to make unbiased statements, but reflects our wish that the conclusions of the conference should not afterwards be attacked for representing industrial opinion.

Such people are, however, invited to bring to the attention of the conference data and other material gathered in the course of their scientific work by sending it by e-mail to conf95@mhsg.cec.be. Data or general comments, if received before 10 November, will be put through a process of peer review. Comments and data received after that date will be acknowledged and read by the steering committee, but will necessarily be given more cursory attention.

In addition to the regular invited participants, the commission also plans to invite a number of interested parties in Europe. Chief among them are the members of the European Parliament who have taken a continuing interest in growth-promoters, as well as consumers' organizations in Europe and elsewhere. They will be allowed to listen to the proceedings, to make statements of predetermined length if they can persuade the chairman of the session concerned that they have something apposite to say and, finally, to take part in a half-day debate on the afternoon of 1 December when the general conclusions of the conference will be presented orally.

Undoubtedly, it will be discovered that there is much still to be learned about the risks of using growth-promoting substances in animal husbandry; one goal is to identify specific areas in which more understanding is needed. On the face of things, there is an urgent need for a better understanding of the effects of trace residues on human physiology. But the ideal will be that the conference should inform the continuing dialogue between the commission and the European Parliament with a substantial basis of understanding.

John Maddox 